\title{
Application of hydrophilic interaction liquid chromatography combined with positive and negative ionization mass spectrometry for the analysis of PSP toxins
}

\begin{abstract}
Hydrophilic interaction chromatography (HILIC) is a useful technique for the separation of PSP toxins that offers a good selectivity and increases the sensitivity of their detection by mass spectrometry (MS/MS). In this study the analytical conditions of the separation and detection were optimized by testing the effect of some components as column, the organic modifier (type and percentage)in the mobile phase, $\mathrm{p}^{\mathrm{H}}$, buffer character and concentration and flow rate. Both types of ionization (positive and negative) were used in the same run. The best results were obtained with a ZIC-HILIC (Merck), using a gradient elution, detecting the toxins in negative ionization mode during the first part of the chromatogram, and in positive mode during the final part. The limits of detection (LODs) and quantization (LOQs) obtained were acceptable for all toxins and low enough for routine monitoring, as well of the analysis time. The matrix effects were observed for some PSP toxins in mussel extracts, so a simple solid phase extraction (SPE) method to clean up the extracts prior the analysis was developed.
\end{abstract}

Keywords: HILIC-MS/MS, Ionization, LOQs, PSP toxins, SPE, ZIC-HILIC column
Volume 2 Issue 2 - 2015

\author{
Juan Blanco,' Araceli E Rossignoli,, ${ }^{1,2}$ Carmen \\ Marino,' Helena Martin' \\ 'Centro de Investigaci \\ ${ }^{2}$ European Union Reference Laboratory for Marine Biotoxins, \\ Spain
}

Correspondence: Juan Blanco, Investigaci, Tel +34 886206364, Email juan.carlos.blanco.perez@xunta.es

Received: March 16,2015 | Published: April 24, 2015
Abbreviations: AOAC, Association of Official Agricultural Chemists; C, N-sulfocarbamoyl Toxins; CE, Collision Energy; dcGTX, Decarbamoyl-Gonyautoxins; dcNEO, DecarbamoylNeosaxitoxin; dcSTX, Decarbamoyl-Saxitoxin; EFSA, European Food Safety Authority; ESI, Electrospray Ionization; EURACHEM, European Analytical Chemistry Network; EURLMB, European Reference Laboratory for Marine Biotoxins; FLD, Fluorescence Detector; GTX, Gonyautoxins; HILIC, Hydrophilic Interaction Liquid Chromatography; HPLC, High Pressure Liquid Chromatography; INTECMAR, Instituto Tecnoloxico para o Control do Medio Marino; JACUMAR, Junta Asesora de Cultivos Marinos; LC, Liquid Chromatography; LOD, Detection Limit; LOQ, Quantification Limit; MBA, Mousse Bioassay; MS, Mass Spectrometry; m/z, Mass to Charge Ratio; NEO, Neosaxitoxin; PFP, Penta fluorophenyl; PSP, Paralytic Shellfish Poisoning; Q1, Quadrupole 1; Q3, Quadrupole 3; RSD, Standard Deviation; RT, Retention Time; S/N, Signal / Noise; SPE, Solid Phase Extraction; SRM, Selected Reaction Monitoring; STX, Saxitoxin; t1, Transition 1; t2, Transition 2; TEF, Toxicity Equivalent Factor; ZIC, Zwitter Ionic Stationary Phase

\section{Introduction}

Paralytic shellfish poisoning (PSP) toxins are potent neurotoxins produced, in marine environments, by three phytoplankton genera (Alexandrium, Gymnodinium and Pyrodinium). The accumulation of PSP toxins in shellfish represents an important public health problem and affects fishery industries. PSP toxins are tetrahydropurine compounds that specifically block the excitation current in nerve and muscle cells, finally resulting in paralysis and other disorders in consumers of contaminated shellfish. ${ }^{1}$ Intoxication by PSP toxins produces several symptoms that include tinkling, sensation or numbness around the lips, numbness of extremities, gastrointestinal problems, difficulty in breathing, and, in fatal cases, death.
The PSP group comprises a total of 57 analogues of $\mathrm{STX}^{2}$ that can be classified into four structural sub-groups: decarbamoyl, carbamoyl, N-sulfocarbamoyl and benzocarbamoyl toxins (Figure 1), in increasing order of toxicity in mammalian bioassays, ${ }^{3}$ having the two latter approximately the same toxicity. ${ }^{4}$ These products are water soluble and, in general, heat stable under moderately acidic conditions but quickly degraded at alkaline $\mathrm{p}^{\mathrm{H}}$, even at room temperature. ${ }^{5}$ The mouse bioassay (MBA) reference method (AOAC Official Method 959.08: Paralytic Shellfish Poison, biological method ${ }^{6}$ ) is internationally recognized for quantifying PSP toxicity and it is used worldwide in PSP monitoring programs. However, some controversy still exists about the most adequate methodology to be used in monitoring programs for the determination of PSP toxicity. The use of animals is becoming increasingly unacceptable because ethical reasons and Commission Regulation (EC) No 2074/ 20057 indicates that the biological tests should be replaced as soon as other internationally validated methods would be available. Alternative methods, including other biological assays, ${ }^{8-11}$ electrophoresis ${ }^{12}$ chemo sensors ${ }^{13}$ and immunoassays, ${ }^{14,15}$ have been investigated in order to replace MBA as a regulatory tool. Some liquid chromatography methods (LC) have been developed although some characteristics of PSP toxins-such as the absence of chromophores in their structure, their extremely polar nature, and their very low volatility-have hindered the development of these kinds of methods for their determination. The most common ones use a combination of LC with either pre- or post-column oxidation that allow for fluorescence detection (FLD). ${ }^{3,16-21}$ One precolumn and one post-column method have been AOAC validated trough a collaborative trials ${ }^{22,23}$ and adopted as First Actions HPLCFLD Official Methods. ${ }^{24,25}$ However, the major drawback of these and other LC methods is that they are time and labor intensive, particularly when used for routine shellfish monitoring. 


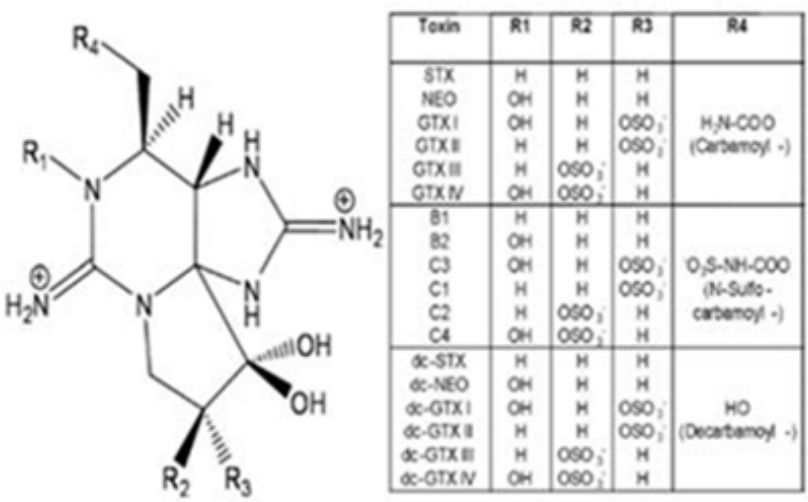

Figure I Chemical structure of PSP toxins. Toxins marked with an asterisk (*) have not been structurally characterized yet. ${ }^{36}$

The presence of a guanidinium moiety, and in some cases a carbamate, in PSP toxins and as a consequence, their capacity to give strong $[\mathrm{M}+\mathrm{H}]+$ ions-makes PSP toxins susceptible of being analysed by Electrospray-ionization-mass spectrometry (ESI-MS). However most common LC methods based in reverse phase LC require ionpairing reagents, such as heptanes sulfonic acid, heptafluorobutyric acid or tetrabutylammonium, in the mobile phase to provide sufficient retention of charged PSP toxins. ${ }^{3}$ Such agents seriously interfere with MS detection by causing suppression of ionization and ion source contamination. ${ }^{19}$ Inadequate sensitivity or matrix effects are additional drawbacks of these methodologies.

Recently new approaches to the analysis of PSP toxins based on hydrophilic interaction liquid chromatography (HILIC) coupled with different types of mass spectrometers have been developed. ${ }^{26-32}$ The HILIC-MS method, in which the chromatography is based on hydrophilic and ion-exchange interactions, overcomes many drawbacks of the previously developed instrumental methods. Not with standing, these techniques may present other drawbacks as reduced resolution when compared with reverse phase (e.g. GTX1 coelutes with GTX2), variable retention times for PSP toxins in different seafood matrices or the need of using relatively long chromatographic runs due to the bad slow response of these separations to mobile phase gradients.

The aim of this study was to develop an improved method, based on the use of HILIC coupled to mass spectrometry, with the capability of discriminating the main PSP toxins, by means of chromatographic separation or by characteristic MS/MS transitions, in a reasonable time for its routine application. A solid phase extraction (SPE) with Strata $\mathrm{X}$ was also optimized in order to reduce or eliminate the possible matrix effects originated by bivalve samples.

\section{Material and methods}

\section{Paralytic shellfish poisoning toxin standards}

Certified reference calibration solutions containing gonyautoxins (GTX1, GTX2, GTX3, GTX4, GTX5), decarbamoyl-gonyautoxins (dcGTX2, dcGTX3), saxitoxin (STX), neosaxitoxin (NEO), decarbamoyl-saxitoxin (dcSTX), decarbamoyl-neosaxitoxin (dcNEO), and $\mathrm{N}$-sulfocarbamoyl toxins ( $\mathrm{C} 1$ and $\mathrm{C} 2$ ) were purchased from the Institute for Marine Biosciences, National Research Council (IMB-NRC) (Halifax, Canada).

\section{Mussel samples}

Mussels (Mytilus galloprovincialis) containing PSP toxins were obtained from a culture raft in Galicia after a Gymnodinium catenatum bloom. All mussels were stored frozen at $20^{\circ} \mathrm{C}$ prior to extraction.

\section{Equipment}

Mass spectral experiments were performed using a HPLC-ESIMS with a Thermo TSQ Quantum Access Max triple quadrupole mass spectrometer coupled to a ThermoAccela ultra high pressure HPLC. Ion selection (transitions) and LC-MS/MS parameters were optimized by infusion of PSP reference solutions. Toxins were infused into an isocratic flow $(200 \mu \mathrm{L} / \mathrm{min})$ of $35 \%$ mobile phase $\mathrm{A}$, constituted by water and $65 \% \mathrm{~B}$, aqueous acetonitrile $(95 \%, \mathrm{v} / \mathrm{v})$, both with $2 \mathrm{~mm}$ ammonium formate and $3.6 \mathrm{~mm}$ formic acid. ${ }^{28}$ Selected reaction monitoring transitions and instrument settings used are given in Table 1.

\section{Methods}

Key parameters -such as type and percentage of organic modifier, $\mathrm{p}^{\mathrm{H}}$, buffer character and concentration and flow rate- were tested to improve peak shape, resolution and sensitivity. Different isocratic and gradient methods were tested using the following HILIC columns: TSK-gel Amide-80® (250 mm x $2 \mathrm{~mm}$, Tosoh Bioscience) analytical column which is packed with silica particles that are covalently bonded with carbamoyl groups; Kinetex HILIC column (50 mm x $2.1 \mathrm{~mm}$, Phenomenex), and Kinetex - PFP column (50 $\mathrm{mm} \times 2.1$ $\mathrm{mm}$, Phenomenex), both with core-shell technology, and ZIC-HILIC column (150 mm x $2.1 \mathrm{~mm}$, Merck) which Zwitter ionic functional groups with a charge balance of 1:1.

\section{Sample solvent and injector mobile phase}

The effect at both, the type of solvent (water, $50 \%$ acetonitrile or $75 \%$ acetonitrile) in which the sample was dissolved and the type of mobile phase (50 to $100 \%$ acetonitrile, 50 or $100 \%$ methanol) used to fill the injector loop of $10 \mu \mathrm{L}$, might have on the detection and quantification of the toxins has also been evaluated.

\section{Toxin quantitation}

Several dilutions of mixtures of PSP toxins standards were prepared and injected 3 consecutive times to determine the limits of quantification (LOQs), by representing relative standard deviation (RSD \%) vs. concentration of each dilution (based on EURACHEM, ${ }^{34}$ ). Limits of detection (LODs) were estimated from LOQs.

\section{Matrix effect evaluation}

Shellfish extracts prepared from a sample of mussels (Mytilus galloprovincialis), that did not contain PSP toxins, were used to investigate the occurrence of possible interferences caused by endogenous (matrix) shellfish compounds in HILIC-MS/MS analysis. PSP standard solutions dissolved in water were spiked to mussel extracts obtained with $\mathrm{HCl} 0.1 \mathrm{M}(1: 1, \mathrm{v} / \mathrm{v})$. Chromatographic separation was carried out with the previously obtained optimized conditions (see 6.4.).

The estimations of matrix effects were performed individually for each toxin according to the following equation:

$$
\mathrm{ME}=[(\mathrm{A}+\mathrm{B})-\mathrm{B}] / \mathrm{A}
$$

Where ME matrix effect, $>1$ indicates the presence of a positive 
matrix effect probable due to enhancement of the ionization and $<1$ indicates a negative matrix effect probably due to ionic suppression.

Once noted the presence of matrix effects, a solid phase extraction (SPE) was done in order to purify the extracts. Strata $\mathrm{X}$ cartridges (Phenomenex) $(60 \mathrm{mg})$ were conditioned with $2 \mathrm{~mL}$ of methanol and $2 \mathrm{~mL}$ of deionized water. $0.3 \mathrm{~mL}$ of mussel extract was loaded onto the cartridges and the PSP toxins eluted with $0.3 \mathrm{~mL}$ of deionized water. Each eluate were collected and analyzed by HILIC-MS/MS using the optimized conditions.

\section{Results and discussion}

\section{Optimization of chromatography}

Stationary phase and mobile phase: The TSK-gel Amide- $80 \AA$ column provided a good separation between epimeric pairs $(\mathrm{C} 1$ and C2, GTX2 and GTX3, GTX1 and GTX4, dcGTX2 and dcGTX3) and also between GTX5 and dcSTX (selectivity coefficient around 1.5) when using water as eluent A and acetonitrile/water (95:5) as eluent B, both containing $2.0 \mathrm{mM}$ ammonium formate and $3.6 \mathrm{mM}$ formic acid. The elutions proposed by Dell'Aversano et al. ${ }^{27}$ (isocratic) and Turrell et al. ${ }^{29}$ (gradient) were used initially with this column. In the first case -with isocratic conditions- early eluting peaks of the GTX and $\mathrm{C}$ groups had good resolution and shape as in the case of STX but the other toxins that elute at the final part of the chromatogram -dcSTX, NEO and dcNEO-showed peaks poorly shaped and consequently very poor resolution. In the second case -under gradient conditionsboth, peak shape and resolution of GTXs, Cs and STX were good and those of dcSTX were slightly better than with isocratic elution. Notwithstanding this was not the case for NEO, and dcNEO, which were hardly detected. Some modification of the gradient were also tested but they only yield marginally better results (for example start with $35 \%$ A, hold for $1 \mathrm{~min}, 35$ to $85 \%$ A over $13 \mathrm{~min}$, hold $2 \mathrm{~min}$, re-equilibrate $21 \mathrm{~min}$ ).

The Kinetex HILIC column was also tested with different mobile phases and flow rates both, in isocratic and gradient mode. This column showed an improvement in the separation of the peaks corresponding to Cs, GTXs and dcGTXs toxins as the acetonitrile percentage (phase B) was increased. However in all cases low percentages of water (around $10 \%$ phase A) at the beginning, increasing until around $25 \%$ in the middle part of the gradient, were necessary to slightly delay the elution of STX group (NEO, dcNEO, dcSTX and STX) in order try to separate all the toxins that elute before it. Also, the presence of ammonium formate in both phases (around $40 \mathrm{mM}$ ) proved to be essential to achieve some separation. Despite slight improvements attained by modifying these conditions, it was not possible to obtain good separations and acceptable peak shape for all toxins (as they either had tails or fronts).

The Kinetex PFP column can behave as HILIC (when the mobile phase has a high organic content) or as reverse phase (when the mobile phase contains a high proportion of water). Neither, HILIC nor reverse phase method gave satisfactory results since in no case an adequate separation of the different toxins was possible. The ZICHILIC was the column which provided the best results. With this column all the PSP toxins tested have good peak shapes and most of them were separated with good resolution in a relatively short analysis time (25 minutes including re-equilibration to initial conditions). The compounds corresponding to the peaks that are not separated or are separated with low resolution are selectively detected by the mass spectrometer, therefore allowing for a correct identification and quantification. With this column the best results were achieved with a smooth gradient starting at $55 \%$ of acetonitrile and with the two mobile phases containing ammonium formate $(2 \mathrm{mM})$ and formic acid (3.6 mM).

The ammonium formate buffer concentration had a significant influence on the retention time with variations of time inversely proportional to their concentration. It seems likely that the Zwitter ionic stationary phase, with sulfobetaine functional groups, which this column has, provides additional selectivity for the Zwitter ionic PSP toxins, but not for the non-zwitter ionic ones, that are not sufficiently separated. Although it is true that some of the toxins (not necessarily epimers) coelute (i.e. GTX1 and GTX2 or STX, dcSTX, NEO and dcNEO) (Figure 2), their identification could be done in any case, by using their specific SRM transitions. This column has already been used ${ }^{28,29}$ but in none of these previous studies had achieved such short run as here, nor had been used with positive and negative ionization neither the studies had included the 13 commercially available PSP toxins.

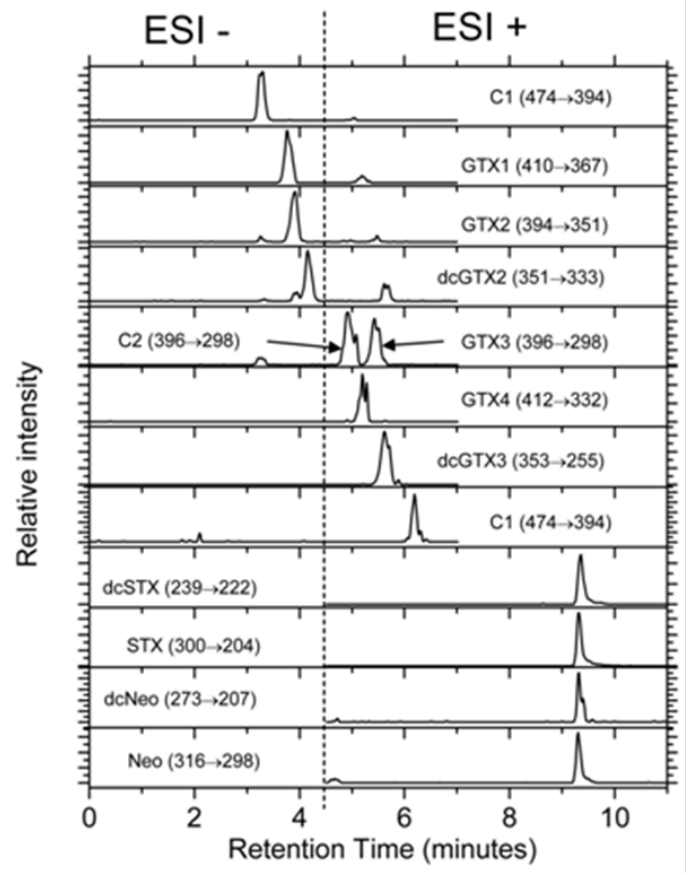

Figure 2 HILIC-MS analysis of a standard mixture containing all PSP toxins commercially available. Analyses were carried out in SRM mode on Thermo TSQ Quantum Access triple quadrupole system. Recommended SRM transitions and type of ionization for each toxin are indicated in Table I. Separations were carried out with final optimized conditions.

Flow rate: Two were the flow rates used throughout the present study. In general $0.2 \mu \mathrm{L} / \mathrm{min}$ showed the best performance for most of the columns tested. However in the case of the ZIC HILIC column (150 $\mathrm{mm} \times 2.1 \mathrm{~mm}$, Merck) turned out to be better to increase it to $0.3 \mu \mathrm{L} /$ $\mathrm{min}$. This flow rate improved the peak shapes without compromising the late eluting toxins, namely dcSTX, STX, dcNEO and NEO and also shortened the analysis time.

\section{Optimization of mass spectrometry}

The most characteristic transitions and the optimal parameters of the mass spectrometer and the ESI interface, for analyzing each individual toxin were determined by direct infusion of PSP reference solutions. The masses of the most abundant pseudo molecular ions or in-source generated fragments of the studied PSP toxins, together 
the retention times, polarities and CID generated fragments proposed for their identification and quantification are shown in Table 1. Both, positive and negative ionization were used. It was found that the toxins that contain a sulfate group in $\mathrm{C} 11$ and that do not lose it in the ESI source are more easily detected using negative instead of the usual positive ionization. This is the case of C1, GTX1, GTX2 and dcGTX2. The optimum response for the other toxins studied that lack the sulfate or loss it by in-source fragmentation was obtained with positive ionization (C2, GTX3, GTX4, dcGTX3, GTX5, NEO, dcNEO, STX and dcSTX). During most of the chromatographic run, polarity switching is not required as the toxins that elute during the first $4.5 \mathrm{~min}$ are preferentially ionized with negative polarity (Figure 2 ), while those with higher retention time are preferentially ionized in positive mode (Figure 2). Capillary temperature was optimized at $360^{\circ} \mathrm{C}$ and the spray voltage at 3500 and $3000 \mathrm{~V}$ for positive and negative ionization, respectively.

Table I Chromatographic and mass spectral data for PSP toxins

\begin{tabular}{|c|c|c|c|c|c|}
\hline Toxin & RT (min) & Type of Ionization & QI & CE & Q3 \\
\hline dcNEO & 9.31 & + & $\begin{array}{l}273(+)(\mathbf{i}) \\
242(+)(f)\end{array}$ & 25 & $\begin{array}{l}207(\mathrm{t} \mid) \\
162.3(\mathrm{t} 2)\end{array}$ \\
\hline GTX2 & 3.90 & - & $\begin{array}{l}396(+)(i) \\
394(-)(i) \\
316(+)(f)\end{array}$ & 25 & $\begin{array}{l}35 \mathrm{I}(\mathrm{t} \mathrm{l}) \\
333(\mathrm{t} 2)\end{array}$ \\
\hline GTX3 & 5.41 & + & $\begin{array}{l}396(+)(i) \\
394(-)(i) \\
316(+)(f)\end{array}$ & 26 & $\begin{array}{l}298(\mathrm{tl}) \\
316(\mathrm{t} 2)\end{array}$ \\
\hline STX & 9.33 & + & $\begin{array}{l}300(+)(i) \\
282(+)(f)\end{array}$ & 30 & $\begin{array}{l}204(\mathrm{t} l) \\
221(\mathrm{t} 2)\end{array}$ \\
\hline NEO & 9.33 & + & $316(+)(i)$ & 25 & $\begin{array}{l}298(\mathrm{t} 1) \\
220(\mathrm{t} 2)\end{array}$ \\
\hline dcSTX & 9.36 & + & $\begin{array}{l}257(+)(\mathrm{i}) \\
239(+)(f)\end{array}$ & 30 & $\begin{array}{l}222.1(\mathrm{t} \mid) \\
\mathrm{I} 26(\mathrm{t} 2)\end{array}$ \\
\hline GTXI & 3.77 & - & $\begin{array}{l}412(+)(i) \\
410(-)(i) \\
332(+)(f)\end{array}$ & 25 & $\begin{array}{l}367(\mathrm{t} l) \\
349(\mathrm{t} 2)\end{array}$ \\
\hline GTX4 & 5.18 & + & $\begin{array}{l}412(+)(\mathbf{i}) \\
410(-)(\mathrm{i}) \\
332(+)(f)\end{array}$ & 25 & $\begin{array}{l}314(\mathrm{t} t) \\
332(\mathrm{t} 2)\end{array}$ \\
\hline GTX5 & 6.18 & + & $\begin{array}{l}380(+)(\mathbf{i}) \\
378(-)(\mathrm{i})\end{array}$ & 30 & $\begin{array}{l}300(\mathrm{t} t) \\
282(\mathrm{t} 2)\end{array}$ \\
\hline dcGTX2 & 4.15 & - & $\begin{array}{l}353(+)(i) \\
351(-)(i) \\
273(+)(f)\end{array}$ & 27 & $\begin{array}{l}334(\mathrm{t} \mid) \\
134.3(\mathrm{t} 2)\end{array}$ \\
\hline dcGTX3 & 5.61 & + & $353(+)(\mathrm{i})$ & 25 & $\begin{array}{l}255(\mathrm{t} l) \\
273(\mathrm{t} 2)\end{array}$ \\
\hline Cl & 3.27 & - & $\begin{array}{l}476(+)(i) \\
474(-)(i) \\
396(+)(f) \\
316(+)(f)\end{array}$ & 26 & $\begin{array}{l}394(\mathrm{t} l) \\
351(\mathrm{t} 2)\end{array}$ \\
\hline C2 & 4.93 & + & $\begin{array}{l}476(+)(\mathrm{i}) \\
474(-)(\mathrm{i}) \\
396(+)(f) \\
316(+)(f)\end{array}$ & 30 & $\begin{array}{l}298(\mathrm{tl}) \\
316(\mathrm{t} 2)\end{array}$ \\
\hline
\end{tabular}

QI: Quadrupole I; Q3: Quadrupole 3; RT: Retention Time

Q1 shows the $m / z$ ratio of the most intense pseudo molecular ions (i) or in-source generated fragments (f) with their ionization polarity inside brackets. Bold-faced ions are the precursors of the fragments for SRM detection, shown in Q3. Italics identify the ions or fragments that to date have not been used in the literature. $\mathrm{t} 1$ and $\mathrm{t} 2$ refer to the two most intense used for identification and quantification of PSP toxins, respectively. $\mathrm{CE}$ is the collision energy.

The combined results of the separation and detection of the main characteristic fragment of each toxin of a standard mixture containing PSP toxins allowed the separation and/or selective detection of a wide range of PSP toxins (Figure 2).

\section{Sample solvent and injector mobile phase}

Although some changes in the chromatograms derived from the use of different sample solvents or fill phases of the injector could be expected, they were not found in this study. Only minor differences were found between using water or acetonitrile at different percentages as sample solvent or injector mobile phase. For this reason, and basically attending to issues of convenience in daily routine and solubility of the compounds, we decided to use water as a solvent of the samples and $50 \%$ acetonitrile: water as the mobile phase of the injector. 


\section{Optimal analysis conditions}

The final conditions recommended for routine operation are the following: ZIC-HILIC column (150 mm x $2.1 \mathrm{~mm}$, Merck) maintained at $30^{\circ} \mathrm{C}$, eluted with a gradient at $0.3 \mathrm{~mL} / \mathrm{min}$, where eluent $\mathrm{A}$ was water, B acetonitrile: water (95:5), both with $2 \mathrm{mM}$ ammonium formate and $3.6 \mathrm{mM}$ formic acid, and the injector mobile phase was $50 \%$ acetonitrile. The gradient program was $55-33 \%$ B over $10 \mathrm{~min}$, hold for $1 \mathrm{~min}$, return to the starting conditions in $2 \mathrm{~min}$ and reequilibrate for $12 \mathrm{~min}$ prior to the next injection. The total analysis time was $25 \mathrm{~min}$. LC-MS/MS analyses were performed in positive and negative ionization and using selected reaction monitoring (SRM) detection with the transitions given in Table 1. These analytical conditions provided better separations of the toxins, particularly for the late eluting PSP toxins, and faster analysis than previously developed HILIC-LC-MS or MS/MS methods.

\section{Toxin quantitation}

The LOQs were determined by using the lowest toxin concentrations that showed a RSD lower than $10 \%$ (based on EURACHEM, $\left.{ }^{34}\right)$. Because LODs and LOQs are often defined as the concentrations which yield a measure peak with $\mathrm{S} / \mathrm{N}$ of 3 or 10 respectively, LODs were estimated from LOQs by a simple equation $(\mathrm{LOD}=\mathrm{LOQ} * 3 / 10)$. Both limits were calculated $(\mathrm{LOQs})$ or estimated (LODs) for the most intense characteristic transition (t1) of each toxin. In this study using HPLC-MS/MS and the ZIC-HILIC column, LODs and LOQs ranged from 17 to $315 \mathrm{nM}$ and from 58 to $1049 \mathrm{nM}$, respectively (Table 2). Although, in general, the LODs for most of the toxins were comparable to those reported previously by Diener et al. $(2007)^{28}$ and Turrell et al. (2008) $)^{29}$ using the same column, this was not the case for some late eluting compounds since, while better LODs were obtained for STX and dcSTX, they worsened considerably for dcNEO. As expected, recently it has been published a new study shows a remarkable improvement in the LODs and LOQs using a most high level equipment and more sensitive as it is an UPLC-MS/MS. ${ }^{33}$

In order to compare the sensitivity of our method to the regulatory value $\left(800 \mu \mathrm{g}\right.$ di $\left.\mathrm{HCl} \mathrm{STX} \mathrm{eq/} \mathrm{kg}^{34}\right)$ LOQs expressed as $\mu \mathrm{g}$ di $\mathrm{HCl}$ STX eq $/ \mathrm{kg}$ shellfish flesh (Table 2) were calculated for each PSP toxin using the toxicity equivalent factors (TEFs) proposed by the EFSA. ${ }^{35}$ All LOQs were below 1/8 of the legal limit except for NEO and dcNEO which were 211 and $156 \mu \mathrm{g}$ di $\mathrm{HCl}$ STX eq/kg respectively. These data suggest that our method has the potential to be used for routine monitoring of shellfish toxicity.

Table 2 Limits of detection (LODs) and quantitation (LOQs) for $\mathrm{m} / \mathrm{z}$ relations of the most intense transition ( $\mathrm{t} \mathrm{l}$ ) obtained for the main PSP toxins using MS/ MS and ZIC -HILIC column

\begin{tabular}{llll}
\hline Toxin & LOD $(\mathbf{n M})$ & LOQ $(\mathbf{n M})$ & LOQ $(\boldsymbol{\mu g} \mathbf{~ d i ~ H C l ~ S T X ~ e q / k g ) ~}$ \\
\hline CI & 58.5 & 195 & 7.3 \\
GTX2 & 63 & 210 & 31.3 \\
dcGTX2 & 61.5 & 205 & 15.3 \\
dcGTX3 & 17.4 & 58 & 4.4 \\
GTXI & 46.8 & 156 & 58.1 \\
GTX4 & 38.7 & 129 & 33.6 \\
GTX5 & 26.1 & 87 & 3.2 \\
GTX3 & 30.6 & 102 & 22.8 \\
C2 & 18 & 60 & 2.2 \\
STX & 38.1 & 127 & 47.3 \\
dcSTX & 17.7 & 59 & 22.0 \\
NEO & 170.4 & 568 & 211.4 \\
dcNEO & 314.7 & 1049 & 156.2 \\
\hline
\end{tabular}

Table 3 Matrix effects obtained for each of PSP toxins standards dissolved in mussel extracts before (a) and after (b) the clean-up with Strata X CI8 cartridges

\begin{tabular}{lll}
\hline Toxin & Matrix Effect (a) & Matrix Effect (b) \\
\hline dcGTX2 & 1.100 & 0.988 \\
dcGTX3 & 1.316 & 0.122 \\
GTX2 & 1.049 & 0.931 \\
GTX3 & 1.117 & 1.099 \\
GTXI & 1.046 & 1.063 \\
GTX4 & 1.161 & 0.950 \\
GTX5 & 1.115 & 1.031 \\
CI & 0.504 & 0.924 \\
C2 & 1.207 & 0.888 \\
STX & --- & 1.128 \\
dcSTX & --- & 1.033 \\
NEO & --- & 0.932 \\
dcNEO & --- & 1.065 \\
\hline
\end{tabular}

\section{Matrix effects and sample clean-up}

The analysis of mussel extracts showed important matrix effects for dcGTX3 (positive, 31\%), GTX4 (positive, 16\%), C1 (negative, $50 \%$ ) and $\mathrm{C} 2$ (positive, 20\%) (Table 3). A significant increase in the pressure of the column was observed during the analysis of these samples due to column clogging. For this reason it was necessary to carry out an intense counter flow wash of the column with 30 volumes of water, 30 volumes of $\mathrm{NH}_{4} \mathrm{Ac} 0.5 \mathrm{M}, 30$ volumes of water and 30 volumes of $\mathrm{ACN} / \mathrm{NH}_{4} \mathrm{Ac}(80: 20 ; \mathrm{v} / \mathrm{v}) \mathrm{p}^{\mathrm{H}} 6.8$. 
The clean-up of the samples by solid phase extraction with Strata $\mathrm{X}$ cartridges was effective in reducing both, the matrix effects and the column clogging. The matrix effect for each PSP toxins decreased considerably, not exceeding in any case 15\% (Table 3). A recent study, ${ }^{32}$ suggests that proteins and other large molecules $(>3 \mathrm{kDa})$ are not responsible for the matrix effects observed and propose a graphitized carbon SPE clean up as a very good option to overcome matrix interference issues traditionally associated with the analysis of PSP in shellfish by LC-MS.

\section{Conclusion}

A HILIC-HPLC-MS/MS method was optimized for the detection and quantification of PSP toxins, allowing a complete discrimination of all PSP toxins relevant for regulation in a 25-minute run, with no need for further confirmatory analyses. The limits of detection and quantification obtained were acceptable even to be applied in the routine monitoring of shellfish toxicity. The fact that an "entry level" mass spectrometer was used makes likely that the use of "mediumhigh level" equipment could improve substantially the sensitivity of this methodology, as very recently it has been published with an UPLC-MS/MS equipment. ${ }^{32}$ Until now, all HPLC-MS/MS for PSP toxins described in the literature only used positive ionization for all compounds. The HPLC-MS/MS method described in this study and the UPLC-MS/MS method (recently published, ${ }^{32}$ ) are the only two that use a combination of both types of ionization (positive and negative) within the same analysis. Although chromatographically the HILIC technology with a zwitter ionic column proved to be the most appropriate, the relatively fast clogging of the column and the matrix effects observed when bivalve's extracts are injected, makes mandatory the use of a preliminary clean-up. The SPE technique developed in this study for the cleanup of mussel extracts was useful to minimize the two problems commented.

\section{Acknowledgements}

This work was funded by the Junta Asesora de Cultivos Marinos (JACUMAR) and the Ministerio de Agricultura, Pesca y Alimentacion (Spain) through the Project: "Comparacion de metodologias para la determinacion de toxinas paralizantes en bivalvos relacionadas con el Paralytic Shellfish Poisoning (PSP). Aplicacion a la acuicultura en Espana" sub Project: "Comparacion de metodologias para la determinacion de toxinas paralizantes en bivalvos relacionadas con el Paralytic Shellfish Poisoning (PSP). Aplicacion a la acuicultura en Galicia". We thank the Departments of Sampling and Biotoxins of the Instituto Tecnoloxico para o Control do Medio Marino de Galicia (INTECMAR) for providing the experimental mussels.

\section{Conflicts of interest}

None.

\section{References}

1. Melloul A, Collin M. Key natural and anthropogenic parameters enhancing the effect of sea level rise: The case of Israel's Mediterranean coast. Ocean \& Coastal Management. 2009;52(1):39-46.

2. Field CB, Mortsch LD, Brklacich M, et al. North America. In: Parry ML, et al. (Eds), Climate Change 2007: Impacts, Adaptation and Vulnerability. Contribution of Working Group II to the Fourth Assessment Report of the Intergovernmental Panel on Climate Change. Cambridge University Press, Cambridge, UK. 2007;pp.617-652.

3. CCSP. Coastal Sensitivity to Sea-Level Rise: A Focus on the MidAtlantic Region A report by the U.S. Climate Change Science Program and the Subcommittee on Global Change Research. US Environmental Protection Agency, Washington, DC, USA. 2009.

4. Karl TR, Melillo JM, Peterson TC. Global climate change impacts in the United States. Cambridge: Cambridge University Press. 2009.

5. IPCC. Climate Change 2007: impacts, adaptation and vulnerability. Contribution of working group II to the fourth assessment report of the intergovernmental panel on climate change. Cambridge University Press, Cambridge, UK. 2007;pp.976.

6. Church JA, White NJ. A $20^{\text {th }}$ century acceleration in global sea level rise. Geophysical Research Letters. 2006;33(1):1-4.

7. Lambeck K, Anzidei M, Antonioli F, et al. Sea level in Roman time in the Central Mediterranean and implications for recent change. Earth and Planetary Science Letters. 2004;224:563-575.

8. Nicholls RJ Small C. Improved estimates of coastal population exposure to hazards released. EOS Transactions. 2002;83(28):303-305.

9. IOC/UNESCO, IMO, FAO, UNDP. A Blueprint for Ocean and Coastal Sustainability. IOC/UNESCO, Paris. 2011.

10. Nicholls RJ, Tol RSJ. Impacts and responses to sea-level rise: A global analysis of the SRES scenarios over the twenty-first century, Philosophical Transactions of the Royal Society A. 2006;364:1073.

11. Marbaix P, Nicholls RJ. Accurately determining the risks of rising sea level, EOS Transactions. 2007;88(43):441-442.

12. Travers A, Elrick C, Kay R. Background Paper: Climate Change in Coastal Zones of the Mediterranean. Priority Actions Programme, Mediterranean Regional Activity Centre, Coastal Zone Management Pty Ltd, Claremont, Australia. 2010.

13. European Commission. Sustainability Report. Luxemburg: Office for Official Publications of the European Communities. 2009;pp.160.

14. Carillo A, Sannino G, Artale V, et al. Steric sea level rise over the Mediterranean Sea: present climate and scenario simulations. Climate Dynamics. 2012;39(9/10):2167-2184.

15. Tsimplis $\mathrm{MN}$, Marcos M, Colin J, et al. Sea level variability in the Mediterranean Sea during the 1990s on the basis of two 2D and one 3d model. Journal of Marine Systems. 2009;78(1):109-123.

16. Tsimplis MN, Baker TF. Sea level drop in the Mediterranean Sea: An indicator of deepwater salinity and temperature changes? Geophysical Research Letters. 2000;27(12):1731-1734.

17. Paulopoulos K, Chalkias C, Karimbalis E. Potential impact of sea level rise on Mykonos, Delos, Rinia islands, In: 6th Pan-Hellenic Geographical Conference, Thessaloniki. 2002;pp.3:469-476.

18. EUROSTAT. Coastal regions. In: Asa Onnerfors (Ed.), Eurostat regional yearbook 2011. Luxembourg: Publications Office of the European Union, Belgium. 2011

19. Coudert E, Larid M. IMAGINE: un ensemble de méthodes et d'outils pour contribuer à la gestion intégrée des zones côtières en Méditerranée, Vertigo-la revue électronique en sciences de l'environnement, Dossier : Les littoraux et la gestion intégrée des zones côtières. 2006;7(3).

20. Devoy RJN. Coastal Vulnerability and the Implications of Sea-Level Rise for Ireland. Journal of Coastal Research. 2008;24(2):325-341.

21. Barth MC, Titus JG. Greenhouse effect and sea level rise: A challenge for this generation, Van Nostrand Reinhold, New York, USA. 1984;pp.324.

22. Milliman JD, Broadus JM, Gable F. Environmental and economic implications of rising sea level and subsiding deltas: The Nile and Bengal examples. Ambio. 1989;18(6):340-345.

23. Warrick RA, Barrow EM, Wigley TML. Climate and sea level change: Observations, projections, implications. Cambridge University Press, Cambridge. 1993. 
24. IPCC. Climate change 2001: impacts, adaptation and vulnerability. Contribution of the working group to the 3rd assessment report of the intergovernmental Panel on Climate Change. World Meteorological Organization, Geneva. 2001;pp.124.

25. IPCC. Climate change 2001: impacts, adaptations and vulnerability. In: McCarthy JJ, et al. (Eds.), Contribution of Working Group II to the Third Assessment Report of the Intergovernmental Panel on Climate Change. Cambridge University Press, Cambridge. 2001;p.75.

26. National statistical Survey of Greece. Population, housing and buildings Census 2001. 2003;p.18

27. Dubois RN. How does a barrier shoreface respond to a sea-level rise? Journal of Coastal Research. 2002;18:2.

28. Bruun P. Sea-level rise as a cause of shore erosion. Journal of Waterways and Harbors Division. 1962:117-130.

29. Rahmstorf S, Foster G, Cazenave A. Comparing climate projections to observations up to 2011. Environmental Research Letters. 2012;7:4.
30. Al-Buloshi A, Al-Hatrushi S, Charabi Y. GIS-based Framework for the Simulation of the Impacts of Sea Level Rise and Coastal Flooding on Oman. Journal of Earth Science \& Climatic Change. 2014;5(10):1-6.

31. Neumann JE, Hudgens DE, Herter J, et al. Assessing Sea-Level Rise Impacts: A GIS-Based Framework and Application to Coastal New Jersey. Coastal Management. 2010;38(4):433-455.

32. Nicholls RJ, Tol RSJ, Vafeidis AT. Global estimates of the impact of a collapse of the West Antarctic ice sheet: an application of FUND. Climatic Changes. 2008;91(1-2):171-191.

33. Valiela I. Global coastal change. Wiley-Blackwell, London. 2006;pp.376.

34. Dasgupta S, Laplante B, Meisner C, et al. The impact of sea level rise on developing countries: a comparative analysis. Climatic Change. 2009;93(3-4):379-388.

35. Nicholls RJ. Coastal flooding and wetland loss in the $21^{\text {st }}$ century: changes under the SRES climate and socio-economic scenarios. Global Environmental Changes. 2004;14(1):69-86. 